\title{
The Green Engineering Education in Chemical Engineering Curriculum at East China University of Science and Technology
}

\author{
Yanyang Wu, Jie Huang, Ling Zhou, Xianmei Zhang, Yixia Gao, Huiming Fan, Zhong Xin* \\ School of Chemical Engineering, East China University of Science and Technology, Shanghai, China
}

Email address:

xzh@ecust.edu.cn (Zhong Xin)

${ }^{*}$ Corresponding author

\section{To cite this article:}

Yanyang Wu, Jie Huang, Ling Zhou, Xianmei Zhang, Yixia Gao, Huiming Fan, Zhong Xin. The Green Engineering Education in Chemical Engineering Curriculum at East China University of Science and Technology. Education Journal. Vol. 10, No. 3, 2021, pp. 83-90. doi: $10.11648 /$ j.edu.20211003.13

Received: May 12, 2021; Accepted: May 29, 2021; Published: June 7, 2021

\begin{abstract}
The green engineering education plays an important role in sustainable development. Motivated by government, industry, and missions of university, the concept of green engineering has been introduced and then gradually enhanced in chemical engineering program at East China University of Science and Technology over these years. Now it becomes an essential part in the curriculum. The green engineering education has been presented in a number of ways including standalone courses, integration into the courses, and modules in experimental, design and practice. There are 5 required standalone courses and 1 elective related to the green engineering in chemical engineering program, and also a series of electives for general education on a green engineering platform at the university level. In the meanwhile, the 12 principles of green engineering have been analyzed and presented by the core courses such as transfer process, separation process, chemical reaction engineering, chemical engineering technology, and chemical engineering design in chemical engineering program. In addition, the green engineering education has been presented by some modules in different kinds of practice, which include experimental, design and practice in the field. All the specified principles have been matched with specific courses. The ability related to green engineering education has been analyzed and assessed by course assessment records and survey from alumni (or senior students), teachers and employers. Both of them indicate that the ability can meet the criteria. This curriculum can be a prototype, for those programs in the developing process of green engineering education within a global, environmental, economic, and societal context.
\end{abstract}

Keywords: Chemical Education Research, Green Engineering Education, Sustainability, Chemical Engineering Curriculum, Green Engineering Principles

\section{Introduction}

Green engineering is regarded as one of the most efficient means of achieving sustainable development in industry [1-3]. The development of green engineering needs well prepared engineers and professionals, who understand the implications of their decisions in their professional careers with regard to the sustainability for this generation and future ones $[4,5]$. Education is crucial to promote green engineering practice. The educational system produces professionals who ultimately develop industrial processes and who run and manage production systems. The integration of green engineering or sustainability concepts into diverse curricula has been recognized as indispensable for providing students with the skills and insights of sustainable development [6-11].

In this paper, the green engineering education (GEE) in chemical engineering (ChE) program at East China University of Science and Technology (ECUST) was presented in details. The ChE program at ECUST was accredited by Engineering Accreditation Commission (EAC) Accreditation Board for Engineering and Technology (ABET) in 2014, which became the first program accredited by ABET in mainland China. And also it was accredited by China Engineering Education Accreditation Association (CEEAA) in 2008 and 2014, respectively. It has ranked the top three on various lists in $\mathrm{ChE}$ program in China. Especially, ECUST has paid highly 
attention to and taken lots of action on GEE. Thus this program is typical of the GEE in ChE in China.

\section{Motivation for GEE}

There has been a rapid increase in public awareness of environmental issues, particularly in safety and health risks from chemicals. More attention has been paid to reducing the human footprint and building the harmonious relationship between human and nature. The importance of introducing green engineering concepts to undergraduate students in China has become increasingly recognized by government, industry, and university. There are several important drivers in place for ChE program at ECUST that have helped GEE practice.

First, it has been motivated by government. As China becomes an important member in green engineering, demand is growing for the scientific and engineering training required in the emerging fields. After China being a signatory on some important international treaties, such as the Basel Convention, the Rotterdam Convention and the Stockholm Convention [12], and especially the Ministry of Environmental Protection (MEP) established in 2009, the chemical supervision is increasingly standard and rigorous in China. In 2015, Chairman Xi announced five concepts of development among which green is taken as the development background. So, the GEE has been increasingly important in many universities in China.

Second, there are many economic incentives, as well as policy drivers advancing green engineering research, development and implementation. The companies have been put under more strict regulations and supervisions of environmental pollution, energy consumption, and material cost. They have to take actions on the technology improvement in the way of green engineering.

Last but not the least, it is the mission of ECUST that educates the responsible engineers. ECUST serves as both the deputy chairman of B.E. and the chairman of M.E. in ChE program in China. It's the responsibility of ECUST to be more involved in GEE and set a good example of ChE program in China. Furthermore, the GEE has been brought forward by the academic vice-presidency at ECUST. He has highly appreciated and taken actions for the GEE, for example, ECUST carried out the Nationwide Summer School on green engineering for college students, conducted Nationwide Lab Safety Management Training for ChE faculties, and organized several green engineering-related symposiums on different levels; In addition, it has become one of the requirements according to the principles of Accreditation. The ChE program at ECUST was accredited by both ABET and
CEEAA. Student outcomes should be met according to their respective criteria [13]. All of these help enhance GEE at ECUST and make it an essential part in ChE Curriculum.

\section{Strategy for GEE}

\subsection{Green Engineering Principles}

In order to incorporate sustainability as design criteria, the 9 principles [14] and 12 principles [15] of green engineering were developed for engineers in 2003, respectively. These Principles are a set of guidelines in terms of sustainable design that, if followed, can lead to useful advances for a wide range of engineering problems. They play a guidance role in the sustainable development by suggesting ways of optimization of products, processes, and systems [16, 17]. As the 12 principles of green engineering were developed from its sister discipline of green chemistry [18], it has been chosen as the criteria during the GEE progress in ChE program at ECUST.

The 12 principles of green engineering can be simplified as follows.

Principle 1 (P1): Inherent rather than circumstantial.

Principle 2 (P2): Prevention instead of treatment.

Principle 3 (P3): Design for separation.

Principle 4 (P4): Maximize mass, energy, space, and time efficiency.

Principle 5 (P5): Output-pulled versus input-pushed.

Principle 6 (P6): Conserve complexity.

Principle 7 (P7): Durability rather than immortality.

Principle 8 (P8): Meet need, minimize excess.

Principle 9 (P9): Minimize material diversity.

Principle 10 (P10): integrate local material and energy flows.

Principle 11 (P11): Design for commercial "afterlife".

Principle 12 (P12): Renewable rather than depleting.

The 12 principles are interdependent, inseparable, mutually reinforcing elements of a design framework. It is important to take the 12 principles in an integral system. It will be dangerous to replace an existing problem by a new one if "green" improvements focus only on a single principle.

\subsection{Match Between Principles and Courses}

It's essential to introduce and present all the 12 principles in courses in order to help students understand them. Several meetings with personnel organized by the academic vice presidency led to supervising and fostering the GEE into the curriculum. The relationship between the 12 principles and courses or modules was discussed thoroughly and then determined by the program committee at ECUST.

Table 1. Match between 12 Principles and Core Courses.

\begin{tabular}{|c|c|c|c|c|c|c|c|c|c|c|c|c|}
\hline & P1 & $\mathbf{P 2}$ & P3 & P4 & P5 & P6 & P7 & P8 & P9 & P10 & P11 & $\mathbf{P 1 2}$ \\
\hline Industrial Ecology & & & & & & $\sqrt{ }$ & & & & & & $\sqrt{ }$ \\
\hline Introduction to Safety Technology & & $\sqrt{ }$ & & & & & & & & & & \\
\hline Transfer Process & & & & $\sqrt{ }$ & & & & & & & & \\
\hline Simulation of Chemical Process Safety & & $\sqrt{ }$ & & & & & & & & & & \\
\hline Unit Operations & & & $\sqrt{ }$ & & & & & & & & & $\sqrt{ }$ \\
\hline Experiments for Unit Operations & & & $\sqrt{ }$ & & & & & & & & & $\sqrt{ }$ \\
\hline
\end{tabular}




\begin{tabular}{|c|c|c|c|c|c|c|c|c|c|c|c|c|}
\hline & P1 & $\mathbf{P 2}$ & $\mathbf{P 3}$ & P4 & P5 & P6 & P7 & P8 & P9 & P10 & P11 & P12 \\
\hline Chemical Engineering Thermodynamics & $\sqrt{ }$ & & & $\sqrt{ }$ & & & & & & & & \\
\hline Separation Engineering & & & $\sqrt{ }$ & & & & & & & & $\sqrt{ }$ & \\
\hline Chemical Reaction Engineering & & & & $\sqrt{ }$ & $\sqrt{ }$ & & & & & & & \\
\hline Chemical Engineering Design & & & & & & & & $\sqrt{ }$ & & $\sqrt{ }$ & & \\
\hline Chemical Process Safety & & $\sqrt{ }$ & & & & & & & & & & \\
\hline Experiments for Chemical Engineering & & & & $\sqrt{ }$ & $\sqrt{ }$ & & & & & & & \\
\hline Chemical Engineering Technology & $\sqrt{ }$ & $\sqrt{ }$ & & & & & & & & $\sqrt{ }$ & & \\
\hline Analysis \& Development of Chemical Processes & & & & & & & & & & $\sqrt{ }$ & & \\
\hline Environmental, Health \& Safety & & & & & & $\sqrt{ }$ & $\sqrt{ }$ & & $\sqrt{ }$ & & & \\
\hline Graduation Practice & & & & & & & & & & & $\sqrt{ }$ & \\
\hline Graduation Design & & & & $\sqrt{ }$ & & & $\sqrt{ }$ & & & & & \\
\hline
\end{tabular}

Note: the check mark $\sqrt{ }$ in the table means the principle would be presented by the course.

As listed in Table 1, all the 12 principles have been integrated into the courses in ChE program at ECUST. Two or three principles have been presented by each core course. They are presented at various levels of theoretical, experimental, practice, and design, etc. These will help the students obtain the way of thinking in accordance with sustainability, then achieve appropriate decisions on the engineering problems within the context and perspective of environmental, economic, and social benefit.

\subsection{The Methodology of GEE}

There are different ways of GEE practice in different kinds of courses.

For the standalone courses, green engineering concepts have been introduced and presented in different modules. The topics such as life cycle assessment, energy saving, and environmental friendliness have been included in Industrial Ecology and Environmental, Health \& Safety. And safety and health risks management have been included in Introduction to Safety Technology, Health, Safety \& Environmental, and Chemical Process Safety, etc.

For the general courses, green engineering elements are presented by problem-based learning. A series of specific problems can be presented in examples and exercises, homework or quiz. Some problems require a quantitative solution, while others integrate both theoretical and application or design with a qualitative solution. The example problems are chosen from a practical process and then a green engineering solution are found and discussed in detail.

For the experimental courses, green engineering concepts have been infused throughout the experimental processes. The students can't get access to the lab until they obtain a pass for the safety and health risks education. Furthermore, the green engineering concepts have been integrated into the experimental process, project and equipment design including environmental influences, waste treatment, and energy consumption, etc. In addition, the students are required to provide suggestions on sustainable development after experiments.

For the design courses, the relationship of engineering, society, and environmental need to be fully considered. The human footprint should be reduced as low as possible. The sustainable development have been taken as the first priority. It can be presented in the factory site location, materials, energy, etc.

\section{GEE Throughout the Curriculum}

The GEE has been reinforced gradually since the first GEE related course in ChE program at ECUST. Now it has become an essential element in this program. It has been incorporated in a number of ways: as a required course, as an elective, as a module in core courses or experimental and design.

\subsection{Standalone Courses}

\subsubsection{In the ChE Curriculum}

The initial green engineering related course was named as Introduction to Environmental Engineering at ECUST. Then several specified courses, including Introduction to Safety Technology, Chemical Process Safety, Environmental, Health \& Safety, Simulation of Chemical Process Safety, and Industrial Ecology, were included in succession. The developing history was shown in Table 2.

As listed in table 2, there are 5 required standalone courses and 1 elective for GEE. All the students will be educated with the knowledge of how the engineering practice will affect society, ecosystems, and environment. The students can be strongly impressed by the systematic courses throughout the four respective years.

The first green engineering-related course Introduction to Environmental Engineering in this program focused on the environmental pollution prevention and control with emphasis on the environmental treatment. During GEE progress over these years, the up-front designs have paid more attention to pollution precaution, environmental benign, and atom economy. The entire chemical or process life cycle has been reinforced progressively. Thus Industrial Ecology in consideration of lifecycles has been included in the $\mathrm{ChE}$ curriculum at ECUST since 2020.

In addition, the education on environmental friendly, safety and health risks from chemicals has obtained highly attention since 2007. It started from the elective Chemical Process Safety. While 4 required courses have been offered and distributed in the four respective years since 2018. Among them, the course Simulation of Chemical Process Safety is at a practice level. The course Health, Safety \& Environmental has been taught by some HSE Supervisors or Safety Supervisors in Mainland China from some famous international chemical 
companies, such as DOWS, Solvay, and BASF, etc. They are very experienced in the HSE design. These approaches can make an impression that sustainable development is joint with the chemical engineering practice.

Table 2. The progress of green engineering related courses in ChE program at ECUST.

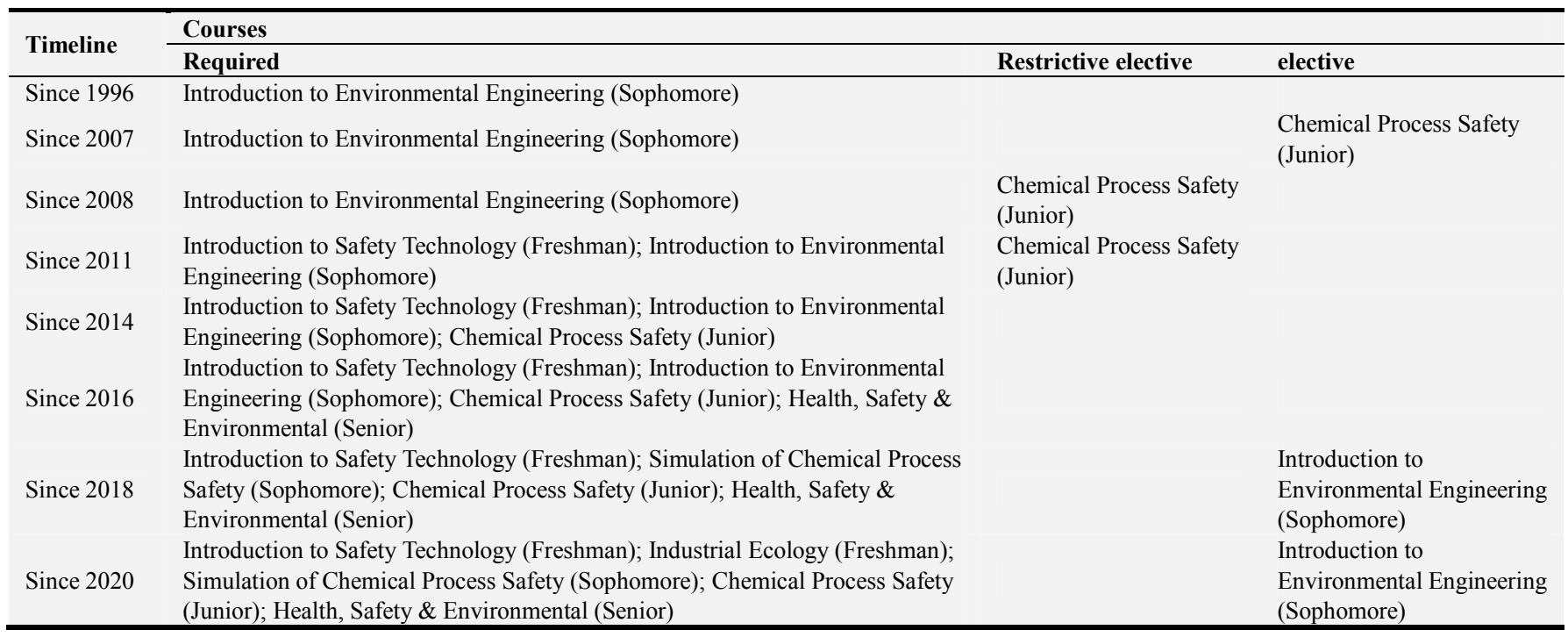

\subsubsection{On the Green Engineering Platform}

As sustainability becomes a more widely accepted concept [19-21], a series of green engineering-related electives (as listed in Table 3) have been developed and then the green engineering platform has been established at a university level The students at ECUST, including those from ChE program, can take any of them and obtain the corresponding credits for general education.

Table 3. Electives on green engineering platform at ECUST.

\begin{tabular}{lll}
\hline Platform & Courses & Credits/Lecture Hours \\
\hline & Biology \& Environment & $1 / 16 \mathrm{hrs}$ \\
& Introduction to Environment \& Health & $2 / 32 \mathrm{hrs}$ \\
& Social development \& Environmental Pollution & $1 / 16 \mathrm{hrs}$ \\
& Introduction to Marine Science & $2 / 32 \mathrm{hrs}$ \\
& Green Chemical Technology & $1 / 16 \mathrm{hrs}$ \\
& Introduction to Environmental Protection of Chemical Industry & $2 / 32 \mathrm{hrs}$ \\
green engineering & Drinking-Water Safety \& Health & $1 / 16 \mathrm{hrs}$ \\
& Introduction to Sustainable Development & $2 / 32 \mathrm{hrs}$ \\
& Green Chemistry \& Catalysis & $1 / 16 \mathrm{hrs}$ \\
& Safety \& Protection of Nuclear Radiation & $2 / 32 \mathrm{hrs}$ \\
\hline
\end{tabular}

\subsection{The Fusion of Green Engineering in Core Courses}

It's a relatively simple way to develop a green engineering related course; nevertheless, such approach tends to result in the students studying for that particular course but not being able to integrate the principles into their professional life [22-24]. By infusing green engineering as a concept into the regular courses, the students can be offered good opportunity to incorporate green engineering principles into their professional lives, through raising their awareness of, and responsibility for the environment and society [25]. All the core courses in ChE program were asked to present some principles. Each one would undertake the GEE task in the context of ABET's and CEEAA's Students Outcomes. Here are some example courses.

\subsubsection{Transfer Process}

It is appropriate for this course to educate students how to maximize material, energy, space, and time efficiency (Principle
4). By comparing monolayer and composite layers equipment in thermal conductivity, students will understand how to reduce the thermal loss and then maximize energy efficiency by a suitable design. The diffusion of the harmful substances and then environmental pollution can be prevented or reduced by employing suitable package material. Now the mass and thermal transfer can be controlled precisely by fabrication of microscale devices containing channels and chambers with different geometry, where "mixing" is accomplished at or near the individual molecule level. Then the efficiency in material, energy, and time can be increased enormously.

\subsubsection{Separation Processes}

The course Separation Processes aims at integrating Principles 3 and 11 of green engineering into its professional knowledge.

Separation of chemical mixtures is one of the two key operations in chemical industry. It consumes most of material, energy, and time in many chemical manufacturing processes. 
The wise separation design, including separation method, mass separating agents, temperature, equipment, etc., can obtain significant savings in material, energy, and time. By introducing case study, such as the enhanced extraction of bio-products, different separation methods were introduced and compared in energy consumption, equipment cost, and potential environmental impacts.

In the meanwhile, the commercial after-life should be considered when choosing a suitable separation process. For example, much wastes and effluents were produced during the conventional extraction of useful products from the minerals. While the definition of wastes or effluents were limited by the technology available. The components that remain functional and valuable in the wastes or effluents can be recovered and purified for reuse and/or reconfiguration by introducing the novel separation technologies or processes. Then commercial end of life will not occur as before.

\subsubsection{Chemical Reaction Engineering}

The course Chemical Reaction Engineering integrates Principles 4 and 5 of green engineering within the professional knowledge.

The chemical reactor design is one of the core tasks in a chemical process. The selection of design elements, including reactor type, temperature, and solvent, etc., is related to the remaining processes such as separation, heat exchange, and use of utilities. High yield can be obtained from small amounts of material through continuous process or process intensification, such as micro-reactors which operate continuously at microscale with efficient mixing.

A reversible reaction can be driven to completion by shifting equilibrium through moving away the outputs continually. The reactive distillation is a typical process of applying the Output-pulled principle. The reaction can be greatly enhanced by continuously removing the products by distillation.

\subsubsection{Chemical Engineering Technology}

Different types of chemical engineering technology which can be representative of some specified Principle of green engineering have been introduced in this course. Particularly, it accounts for Principles 1, 2 and 9. Taking the synthesis of ammonia by nitrogen and hydrogen as an example. Each atom has been utilized at a full scale. There's no potential by-product. The students can be impressed by the principle of Inherent rather than circumstantial.

Besides, vinyl chloride can be obtained mainly through four processes. Among them, the oxychlorination way can consume all the chlorine, correspondingly prevent its pollution, and then require no after-treatment. It illustrates the essence of the Principle of Prevention instead of treatment. Nowadays this process accounts for 93\% market shares of vinyl chloride in the world.

In addition, the separation of cracking gases including hydrogen, methane, ethylene, and propylene has been taken as an example of integrating local material and energy flows. The cooling systems at different temperatures are needed in such process. The cascade cooling system, which can take advantage of energy and material flows available, has been utilized in the order of increasing temperature. This approach can decrease energy consumption greatly.

\subsubsection{Chemical Engineering Design}

The course Chemical Engineering Design mainly infuses Principles 8 and 10 of green engineering. The design of chemical process is always faced with the selection of product purity and equipment size. There is no need for the overdesign and unusable capacity or capability which will obviously increase the cost and energy consumption.

Meanwhile, the selection of factory site and energy source should follow the principle of integrating local material and energy flows. That will decrease the transportation cost, maximize the energy available, and reduce the potential risks from the chemicals during transportation.

As the 12 principles are inseparable, interdependent, mutually reinforcing components, the courses in the program are also interdependent and may involve more principles than the ticked ones in table 1 . The broader vision with all the 12 principles should be presented for the students.

\subsection{Modules in the Practice}

The GEE has been presented by some modules in different kinds of practice, which include experimental, design and practice in the field.

\subsubsection{Experimental}

Experiment is an essential part in ChE program. It's more close to the practical process. Students can be impressed by experiments more than lectures. As accredited by both ABET and CEEAA, the green engineering concepts have become essential parts in the experimental and lab management.

The lab access system has been upgraded since 2011. The contents involving safe and health risks control, environmental assessment, and energy saving have been included on the website http://hgxyaqpt.ecust.edu.cn. The students should study the lab safety regulations, general risks from chemicals, and environmental and energy assessment at first and then pass the examination on website before access to the lab. Then specific SOP and HAZOP analysis will be lectured online and offline by the advisors.

The experimental apparatus have been renewed progressively within the strict contexts. The experimental design has been improved in full consideration of green engineering or sustainability. For example, various waste (gas, liquid, or solid) treatment systems have been included into the labs, the off gas treatment system has been added into the absorption system, the extraction solvent has been changed into more environmental friendly and safe one. All of these will help impress the students with green engineering concepts.

In the meanwhile, the green engineering concepts have been integrated into the specified experiments benefited from Information Technology. For example, the styrene production with annual output of about 5 tons by dehydrogenation of ethylbenzene was provided for the undergraduates in $\mathrm{ChE}$ program. It was at pilot-plant scale, which was very helpful in training the students with engineering concepts. The apparatus 
was renovated by means of information technology and process simulation. It has become a simulation device with the actual size. The students can perform both the semi-physical motion off-line simulation and Virtual Reality (VR) online simulation. There's no feedstock and output in this system. The students can easily and also safely manipulate various units, valves, instruments, and simulation Digital Signal Controller (DSC). They can perform the start-ups, steady-state adjustment, shut-ups, and incident treatment, etc. and then understand much better the chemical production and process controls.

In addition, the study on reaction kinetics in microchannel reactor has been developed from the original scientific achievements by faculties. The safety, efficiency and environmental issues have been presented in such experiment. The students can comprehend the green engineering characteristics, and thus the optimization and preliminary design of microchannel.

\subsubsection{Design}

The green engineering concepts was required in graduation design or capstone since 2010. EHS elements have become an essential criteria in the rating system. The grade will be partially dependent on the comprehension of environmental regulations, optimization of energy consumption, reduction of solid wastes, effluents, and off-gas, and HAZOP analysis, etc. In the meanwhile, the economic analysis should be carried out within the societal context to obtain a broader vision of green engineering or sustainability.

\subsubsection{Practice in the Field}

The practice involves cognitive practice and graduation practice. Both of them provide students with internship experience in the field. Several measures have been taken to promote GEE.

First, the risks control has been reinforced in this course. The students are asked to wear the protective equipment and appropriate clothes before access to the production area. The safety instructions and potential risks will be notified by the advisors on site in details.

Second, the green engineering concepts, including environmental protection, energy consumption, and safety, are shown in the field design. It can impress students much more than a lecture and understand how to deal with the similar situation in future.

Besides, a typical design in consideration of life cycles will be presented in the field. It will introduce the life cycle consequences and societal dimensions of their designs. The broad education is necessary for the undergraduates to understand the impact of engineering solutions in a global, economic, environmental, and societal context [17].

\section{Results and Discussion}

\subsection{The GEE at ECUST}

According to the curriculum, GEE has been paid highly attention in ChE at ECUST. It involves in standalone courses, green engineering platform, integration into all the core courses, infusion into experimental processes, modules in design, etc. The number of related courses, the depth and width into GEE, and the infusion throughout all the core courses are quite impressive. Although it is a difficult practice within the already overcrowded curriculum, green engineering has become an essential part in ChE curriculum through the efforts over these years. It gives the students an opportunity of being immersed by the green engineering or sustainability concepts. Then they can provide a design or process in full consideration of environmental, economic, and social benefit at the first beginning. The GEE practice at ECUST has given a typical curriculum towards the sustainability. The whole sketch of GEE in ChE program at ECUST can be illustrated in Figure 1.

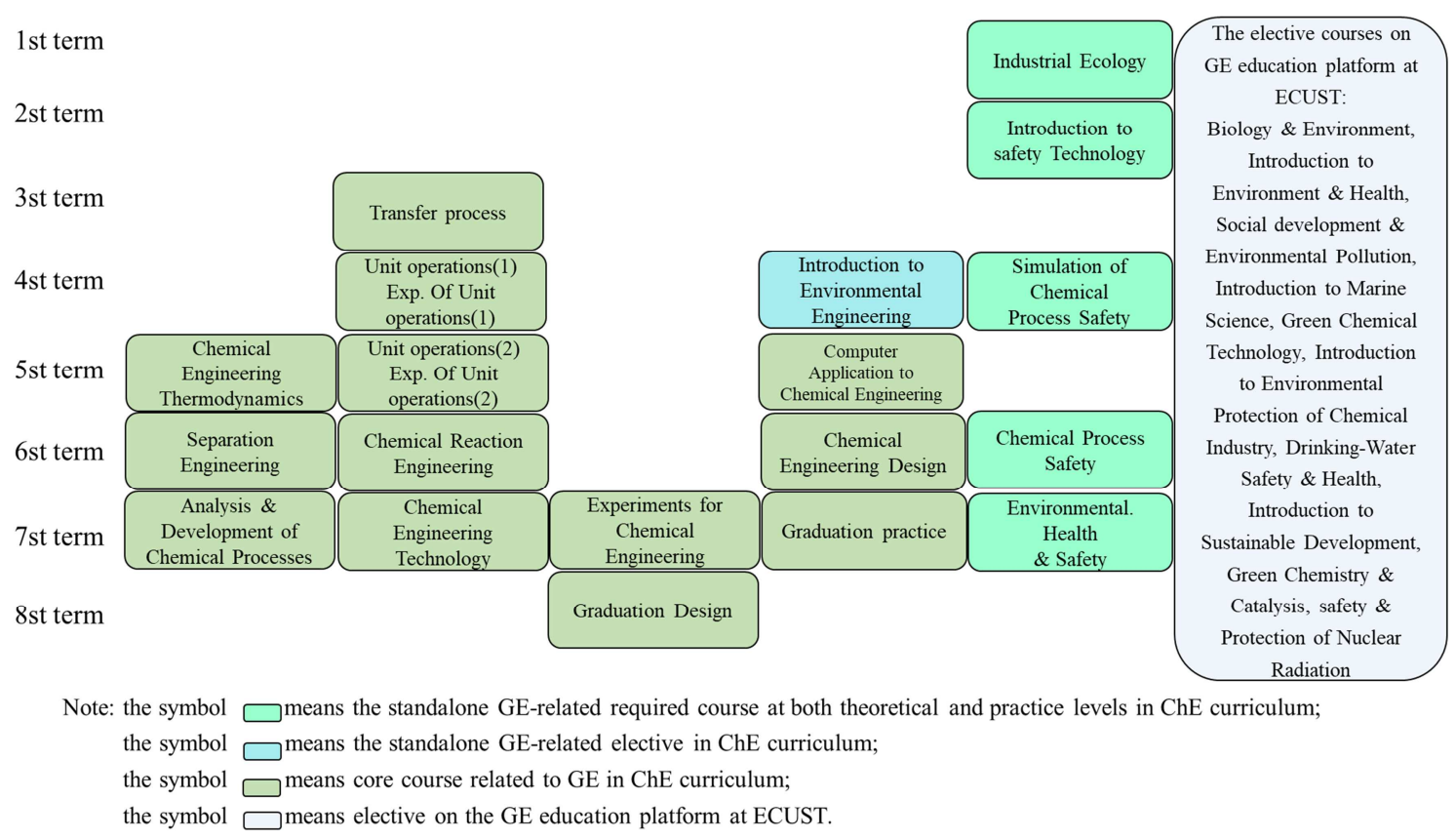

Figure 1. The sketch of GEE in ChE at ECUST. 


\subsection{The Effects of GEE}

The ability related to GEE has been analyzed and divided into three parts, which are: (1) A1: engineering solutions in a global, economic, environmental, and societal context; (2) A2: environmental and sustainable development; and (3) A3: professional and ethical responsibility.

Assessments have been made to determine if a desired Student Outcome is met or not through various methods. Direct and indirect assessment tools have been established and used to measure the curriculum achievement of Student Outcomes, and to provide a mechanism for continuous program improvement. The tools include Course Assessment Records (CAR) and Survey from alumni (or senior students), teachers and employers.

The CAR involves extracting specific categories of student work from several classes. The evaluation parameters used include quizzes, examinations, exercises, oral presentations, reports, projects, or experiments. A threshold, i.e. $80 \%$, is set for all the abilities. The weighted average score of the specific Student Outcomes for all the courses were calculated for different academic years. The weight coefficients come from the level of importance on Student Outcomes for each course reviewed and discussed by the program committee. The results have been presented in figure 2 . For the graduates in 2020 and 2018, all outcomes can meet the criteria of $80 \%$. The Student Outcomes in 2020 are greater than those in 2018, which means the abilities related to green engineering are improved through enhancing GEE. In addition, the questionnaire survey has been carried out on the self-assessment of the three outcomes on GEE for graduates in 2020 , respectively. As can be seen from figure 2, all the abilities by the self-assessment are lower than those from CAR, which may be caused by difference between the qualitative and quantitative assessment. Still they are greater than $80 \%$.

In the meanwhile, the questionnaire survey about the effects of GEE has also been carried out on industry/employers in 2020 and 2018, respectively. As listed in table 4, all the specific abilities have been highly evaluated by the employers. $100 \%$ employers think the graduates in ChE at ECUST have strong or very strong ability of both A1 and A3. Only 6.67\% employers think the graduates in ChE at ECUST have normal ability of A2.

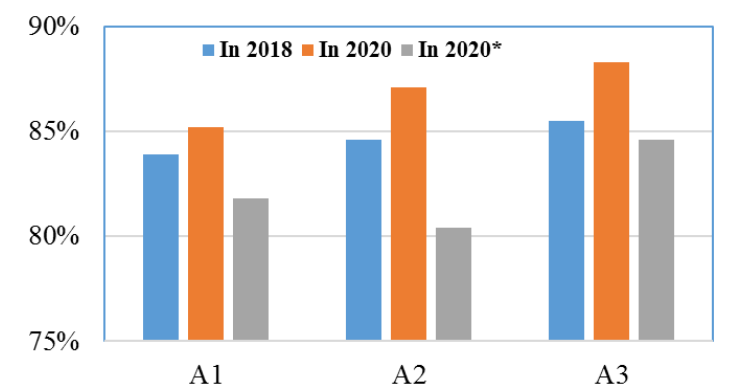

Figure 2. The three outcomes on GEE in 2018 and 2020. In 2020* means the self-assessment by the graduates in 2020.

Table 4. The employers'evaluations with respect to one specific ability.

\begin{tabular}{|c|c|c|c|c|}
\hline Ability Evaluation & Very strong & Strong & Normal & Weak \\
\hline A1: engineering solutions in a global, economic, environmental, and societal context & $46.77 \%$ & $53.33 \%$ & $0 \%$ & $0 \%$ \\
\hline A2: environmental and sustainable development & $26.67 \%$ & $66.67 \%$ & $6.67 \%$ & $0 \%$ \\
\hline A3: professional and ethical responsibility & $53.33 \%$ & $46.77 \%$ & $0 \%$ & $0 \%$ \\
\hline
\end{tabular}

\section{Conclusions}

Motivated by the government, industry, and university, the GEE has been introduced and enhanced in ChE program at ECUST since 1996. It has attached highly importance to the GEE, which has become an essential element. The 12 principles of green engineering have been integrated into all the core courses throughout $\mathrm{ChE}$ curriculum. The relationship between the specified principle and course reveals that all the 12 principles have been covered and presented in the curriculum. It has been incorporated in a number of ways such as specified courses, integration into core courses, and module in practice. There are 5 required standalone courses and 1 elective related to the green engineering in $\mathrm{ChE}$ program, and also a series of electives for general education on a green engineering platform at the university level. Besides, the safety and health risks from chemicals, environmental protection, energy consumption, and more importantly, life cycles have been considered and included in the experimental, design, and practice in the field at practice level. The ability related to GEE has been assessed by CAR and Survey from alumni (or senior students), teachers and employers. Both of them indicate that the ability can meet the criteria.

While the GEE is still on the way, it is hoped that the systematic integration of GEE in the ChE curriculum will empower the graduates to have strong impacts in helping the accomplishment of the goals of green design and sustainability.

\section{References}

[1] S. L. Wilkinson, "Green" is practical, even profitable. No longer a luxury, green chemistry becomes a central strategy for sustainable firms, Chem. Eng. News 75 (A4) (1997) 35-43.

[2] D. T. Allen, D. R. Shonnard, Green engineering: environmentally conscious design of chemical processes and products, AIChE J. 47 (9) (2001) 1906-1910.

[3] P. T. Anastas, M. M. Kirchhoff, Origins, current status, and future challenges of green chemistry, Acc. Chem Res. 35 (9) (2002) 686-694.

[4] U.S. Environmental Protection Agency, Green Engineering web site, http://www.epa.gov/opptintr/greenengineering/index.html, 2005. 
[5] R. P. Hesketh, M. H. Gregg, C. S. Slater, Green Engineering Education, Sustainability Science and Engineering: Defining principles, 2006, 47-87.

[6] R. Lozano, Diffusion of sustainable development in universities' curricula: an empirical example from Cardiff University. J. Clean. Prod., 2010, 18 (7), 637-644. http://dx.doi.org/10.1016/j.jclepro.2009.07.005.

[7] S. I. Olsen, P. Fantke, A. Laurent, M. Birkved, N. Bey, M. Z. Hauschild, Sustainability and LCA in engineering education A course curriculum, Procedia CIRP 69 (2018) 627-632.

[8] F. J. Lozano, R. Lozano, P. Freire, C. J. Gonzalez, T. Sakao, M. G. Ortiz, A. Trianni, Angela Carpenter, Tomas Viveros, New perspectives for green and sustainable chemistry and engineering: Approaches from sustainable resource and energy use, management, and transformation, Journal of Cleaner Production 172 (2018) 227-232.

[9] K. Ortegon, Life Cycle Engineering in an Industrial Engineering undergraduate program, from the classroom to the real life of students, Procedia CIRP 80 (2019) 613-618.

[10] D. W. Knight, D. A. Kotys-schwartz, "Further Along the Engineering Pathway: The Impact of Design Spaces on the Development of Engineering Student Outcomes," in Research in Engineering Education Symposium, 2016, pp. 1-9.

[11] M. Z. Hauschild, C. Herrmann, S. Kara, An Integrated Framework for Life Cycle Engineering, Procedia CIRP, 2017, 61: 2-9.

[12] H. Wang, Z. Yan, H. Li, N. Yang, K. M. Y. Leung, Y. Wang, R. Yu, L. Zhang, W. Wang, C. Jiao, Z. Liu, Progress of environmental management and risk assessment of industrial chemicals in China. Environ. Pollut. 2012, 165, 174-181. ISSN 0269-7491, doi: 10.1016/j.envpol.2011.12.008.

[13] ABET, Accreditation Criteria \& Supporting Documents, https://www.abet.org/accreditation/accreditation-criteria/, 2020.

[14] M. A. Abraham, N. Nguyen, "Green engineering: defining the principles" results from the sandestin conference. Environ. Prog. 2003, 22, 233-236.

[15] P. T. Anastas, J. B. Zimmerman, Design through the 12 principles of green engineering. Environ. Sci. Technol. 2003, 37 (5), 94A-101A.
[16] Office of Management and Budget, Office of Information and Regulatory Affairs, 2003 Report to Congress on the Costs and Benefits of Federal Regulations Washington, DC, 2003.

[17] P. T. Anastas, J. B. Zimmerman, Chapter 2: The Twelve Principles of Green Engineering as a Foundation for Sustainability, Sustainability Science and Engineering: Defining principles, 2006.

[18] J. M. Kira, X. X. Matus, J. B. Zimmerman, Green chemistry and green engineerinin China: drivers, policies and barriers to innovation, Journal of Cleaner Production, 2012, 32: 193-203.

[19] R. A. Fenner, C. M. Ainger, H. J. Cruickshank, P. M. Guthrie, Embedding sustainable development at Cambridge University Engineering Department. Int. J. Sust. Higher Edu. 2005, 6 (3), 229-241. http://dx.doi.org/10.1108/14676370510607205.

[20] P. Glavic, R. Lukman, R. Lozano, Engineering education: environmental and chemical engineering or technology curricula e a European perspective. Europ. J. Eng. Edu. 2009, 34 (1), 47-67. http://dx.doi.org/10.1080/03043790802710193.

[21] J. Segalàs, D. Ferrer-Balas, K. F. Mulder, What do engineering students learn in sustainability courses? The effect of the pedagogical approach. J. Clean. Prod. 2010, 18, 275-284. http://dx.doi.org/10.1016/j.jclepro.2009.09.012.

[22] C. Boks, J. C. Diehl, Integration of sustainability in regular courses: experiences in industrial design engineering. J. Clean. Prod. 2006, 14 (9-11), 932-939.

[23] N. Lourdel, N. Gondran, V. Laforest, C. Brodhag, Introduction of sustainable development in engineers' curricula. Problematic and evaluation methods. Int. J. Sust. Higher Edu. 2005, 6 (3), 254-264.

[24] D. J. Peet, K. F. Mulder, A. Bijma, Integrating SD into engineering courses at the Delft University of Technology. The individual interaction method. Int. J. Sust. Higher Edu. 2004, 5 (3), 278-288.

[25] F. J. Lozano, D. Huisingh, M. Delgado, An interconnected approach to incorporate sustainable development at Tecnológico de Monterrey. Int. J. Sust. Higher Edu. 2009, 10 (4), 318-333. 